\title{
A 'TEORIA DA PRÁXIS': RETOMANDO O REFERENCIAL MARXISTA PARA O ENFRENTAMENTO DO CAPITALISMO NO CAMPO DA SAÚDE
}

\author{
THE 'THEORY OF PRAXIS:' RETRIEVING THE MARXIST FRAMEWORK TO CONFRONT CAPITALISM \\ IN THE HEALTH FIELD
}

Regina Helena Simões Barbosa ${ }^{1}$

Resumo Este ensaio tem a intenção de re-colocar o marxismo - como corpo epistemológico, teórico, metodológico e político voltado para a superação do capitalismo - na pauta do debate conceitual e político do campo da Saúde Coletiva. Discute o campo simbólico como campo de expressão de ideologias que sustentam o capitalismo e que utiliza, dentre outras estratégias, o silenciamento sobre o marxismo, e mesmo sobre o capitalismo, para esvaziar a crítica e o questionamento político. Relaciona estes mecanismos à saúde, identificando alguns campos onde o capitalismo opera nesta área. Apresenta alguns fundamentos filosóficos, teóricos e metodológicos da 'teoria da práxis', destacando a unidade indissolúvel entre teoria crítica e ação transformadora. Por fim, conclama os profissionais, pesquisadores e educadores do campo sanitário a se (re)engajarem na luta contra o capitalismo, retomando a bandeira do socialismo, rumo à conquista do efetivo direito à saúde.

Palavras-chave marxismo; capitalismo; socialismo; saúde coletiva.

\begin{abstract}
This essay is intended to retrieve Marxism as an epistemological, theoretical, methodological and political body aimed toward overcoming Capitalism in the political and conceptual debate agenda in field of Collective Health. It discusses the symbolic field as a field for the expression of ideologies that underpin capitalism and which uses, among other strategies, the silencing of Marxism, and even of capitalism, to eliminate criticism and political questioning. It relates these mechanisms to health, identifying some fields in which capitalism operates in this area. It presents a few philosophical, theoretical and methodological foundations of the 'theory of praxis,' highlighting the indissoluble unity between critical theory and transformative action. Finally, it urges health care practitioners, researchers and educators to (re)engage in the struggle against Capitalism, taking up the banner of Socialism aiming to achieve the actual right to health.
\end{abstract}

Keywords Marxism; Capitalism; Socialism; collective health. 


\title{
Introdução: a quem serve o conhecimento?
}

\author{
Se é verdade que o planeta está sob a \\ ameaça de graves calamidades, \\ então aqueles que crêem conhecer \\ essas calamidades antecipadamente \\ não terão o dever de abandonar \\ o tradicional recato que os cientistas \\ impõem a si próprios?
}

(Bourdieu, 2002).

Este ensaio 2 tem a intenção de re-colocar o marxismo - enquanto corpo epistemológico, teórico, metodológico e político voltado para a superação do capitalismo - na pauta do debate conceitual e político do campo da Saúde Coletiva.

Nos tempos que correm, em que o campo simbólico encontra-se profundamente dominado por conceitos e valores ideológicos ${ }^{3}$ que justificam e sustentam o capitalismo em todas as suas dimensões, advogamos que a 'teoria da práxis', uma das denominações do marxismo, é mais necessária do que nunca, tanto para desmascarar a (ainda) renitente tese da neutralidade do conhecimento, como para nos conclamar, mais uma vez, ao enfrentamento do capitalismo, em particular no campo científico-acadêmico.

Este debate, a nosso ver, tem estado ausente e/ou silenciado na Saúde Coletiva. A propósito do 'silêncio' (que não é dos 'inocentes'), percebemos que esta estratégia para esvaziar a crítica e o questionamento político assumiu um duplo aspecto: por um lado, silêncio sobre o marxismo e, por outro, também sobre o capitalismo, este último tornado o 'eterno presente', a tal ponto 'naturalizado' que não mais necessita de reconhecimento e nomeação.

Vivemos tempos nebulosos, em que as palavras perdem seus sentidos históricos e políticos, os significados tornam-se múltiplos, ambíguos, vagos, retóricos e, mesmo quando se assume um tom de crítica, muitas vezes esta é superficial e genérica, contra uma sociedade abstrata, contra poderes abstratos, contra processos que, embora reconhecidamente tornem a sobrevivência humana ameaçada, não têm denominação e, portanto, entendimento.

Ao analisar esta questão, Bourdieu (2000) classificou como 'imperialismo simbólico' a significativa supressão, do léxico sociológico contemporâneo, de conceitos tais como capitalismo, classe, exploração, dominação, desigualdade e outros, revogados sob o pretexto de obsolescência ou impertinência. Para este autor, a gravidade desta questão, no terreno das Ciências Sociais, é que essa 'nova vulgata' ideológica instituiu como conceitos 'universais' seus próprios termos - diversidade, identidades, diferenças, fragmentação, 
etc. - na constituição do campo teórico genericamente denominado 'multiculturalismo' (Bourdieu, 2000).

Wood (1996), ao criticar as teorias da pós-modernidade que dão sustentação às idéias de fragmentação e dispersão, características do capitalismo contemporâneo, identifica que

Estruturas e causas foram substituídas por fragmentos e contingências. Não existe uma coisa chamada sistema social (por exemplo, o sistema capitalista) com sua própria unidade sistêmica e suas 'leis de movimento'. Há somente muitos tipos diferentes de poder, opressão, identidade e 'discurso' [...] Só existem diferenças anárquicas, desconectadas e inexplicáveis. Pela primeira vez, estamos diante de uma contradição em termos: uma teoria de mudança de época histórica, baseada na negação da história (Wood, 1996, p. 121-122).

Ao criticar o sentido abstrato, distanciado do mundo concreto, das teorias sociais atualmente hegemônicas, Castro (2000) também argumenta que a expressão das tendências neoliberais no conhecimento acadêmico movemse "...na 'luta discursiva', ou seja, na 'luta pelo controle dos termos e regras do discurso', e rompem com a 'unidade-de-teoria-e-prática-marxista, a revolução como processo'"'(2000, p. 98). Como decorrência política deste processo, a própria ênfase numa agenda de defesa por diferenças, pela afirmação de identidades diversas, por igualdade de oportunidades e direitos 'parcializados' - para mulheres, negros, indígenas, homossexuais e, agora, os 'novos pobres' - reflete uma posição “...sem investimento nas condições materiais que tornaria possível o exercício dos direitos" (Castro, 2000, p. 99). Identificadas como 'pós-estruturalistas', ou 'pós-modernas', estas correntes infiltraram-se propagando 'elogios às diferenças' que fragmentam a abordagem e o enfrentamento do capitalismo enquanto totalidade social, reduzindo a compreensão das relações sociais a práticas discursivas. ${ }^{4}$

Ao analisar os processos de 'neutralização' do conhecimento crítico, Oliveira (2005) aponta como categorias que nasceram questionadoras da ordem vigente vão perdendo seu potencial crítico na medida em que são absorvidas, integradas e, assim, 'naturalizadas'. Por exemplo, na crítica às correntes feministas que abandonaram a perspectiva de enfrentamento do capitalismo nas lutas por igualdade de gênero, Castro mostra como a ênfase numa agenda de defesa por diferenças, pela afirmação de identidades diversas, por igualdade de oportunidades e direitos para 'as mulheres' - tomadas como categoria universal, sem relação com as desigualdades de classe - reflete uma posição “... sem investimento nas condições materiais que tornaria possível o exercício dos direitos". Portanto, a referência desta tendência é "...a uma mulher genérica, desterrada da classe e da classe-e-raça” (Castro, 2000, p. 99). No mesmo sentido, Giffin aponta o quanto a luta feminista 
perdeu seu potencial crítico e contestador na medida em que seus termosgênero, inclusive - foram apropriados por agências e organismos internacionais que atuam para minorar as contradições geradas pelo/no capitalismo. Entre outras consequências, esta 'apropriação' política obscureceu as persistentes desigualdades de classe e raciais/étnicas, inclusive entre as próprias mulheres (Giffin, 2002).

Se assumimos, com o marxismo, que nenhuma ciência social é neutra e que toda teoria ou modelo explicativo da sociedade implica, mesmo que não explicitamente, em um posicionamento político, como nós - professores, pesquisadores, acadêmicos em geral - temos nos colocado, individual e coletivamente, em relação a esta sociedade (no mínimo) problemática?5 Pergunta incômoda, particularmente na Saúde Coletiva, um campo historicamente marcado pelo envolvimento e compromisso político com a coletividade e com o bem público.

Para responder à pergunta, pensamos ser necessário analisar as políticas científica e educacional que vêm regendo os processos de trabalho e a produção científica nas instituições públicas de ensino e pesquisa nas últimas décadas. Neste terreno, constatamos o quanto tem sido pouco debatido, entre nós, o fato de que muitas destas políticas são formuladas e, em parte, financiadas por agências internacionais, como Banco Mundial (BM), que têm como um de seus objetivos conectar as instituições educacionais (e também de saúde) ao mercado e, mais amplamente, converter a educação (e a saúde) em mercadoria, negociada, inclusive, na Organização Mundial do Comércio (OMC) (Santos, 2004; Rizzotto, 2000). Assim, conscientemente ou não, nos tornamos parte "[...] das engrenagens de um grande sistema de mercado globalizado de produção científica e tecnológica", do qual fazem parte, entre outros atores 'interessados', grandes corporações editoriais internacionais que, através dos vários mecanismos de avaliação instituídos, detêm "o domínio sobre a informação resultante das pesquisas financiadas com dinheiro público" (Ramírez-Gálvez, 2000, p. 16). Paralelamente, estabelecem-se relações obscuras entre recursos públicos e privados, sendo que, em muitas situações, o primeiro beneficia o segundo, tal como nos processos de inovação tecnológica que resultam de conhecimentos produzidos em instituições públicas e que vão beneficiar diretamente a produção de bens e serviços privados (Neves e Pronko, 2008).

Como vem alertando Leher,

No plano educacional, é sobejamente conhecido que as políticas de ajuste estrutural do Banco Mundial contribuíram decisivamente para inviabilizar a educação e em particular as universidades da África subsaariana e, no caso da América Latina, impediram que os governos mantivessem as universidades entre as prioridades das políticas públicas, contrapondo o direito aos conhecimentos científico, 
tecnológico e artístico à alfabetização e às primeiras letras, estas últimas tidas apenas como ações focalizadas para os que foram eleitos como os mais pobres. Como desdobramento, o fornecimento privado conheceu um crescimento colossal no Brasil e em toda a região, aprofundando o neocolonialismo (Leher, 2003, p. 15-16).

No que diz respeito ao trabalho acadêmico, esses processos instalam e promovem acirrada competição entre pares e a fragmentação dos processos de produção do conhecimento que, ao invés de rumarem no sentido da tão almejada interdisciplinaridade, fecham-se em grupos de pesquisa cada vez mais especializados, corporativos e concorrentes entre si. Os efeitos danosos desta política, inclusive sobre a saúde dos próprios pesquisadores, começam a ser percebidos e analisados por alguns colegas (Luz, 2005).

Assim, nesta 'linha de montagem fordista-taylorista acadêmica' , 6 a produção do trabalho científico se individualiza e se fragmenta e pesquisadores abandonam qualquer perspectiva de atuação crítica e/ou coletiva. Após décadas de lutas que possibilitaram a construção de um projeto de universidade e de instituições de pesquisa públicas, comprometidas com os interesses estratégicos do país e com as necessidades da população brasileira, reitero a incômoda pergunta: como temos enfrentado essas políticas educacionais que, de formas claras ou sutis, infiltram-se em nossas instituições e passam a regê-las através da lógica privatista, competitiva e voltada para o mercado do conhecimento? Como temos nos colocado em relação a uma política acadêmica que não se preocupa com a qualidade e/ou com o compromisso social do conhecimento?

Como alertam Ramírez-Gálvez (2009), estes processos de trabalho estruturam-se não só no plano objetivo como na subjetividade dos pesquisadores, uma vez que

[...] esse tipo de política age através da autorregulação dos indivíduos, incentivados a serem sujeitos ativos e responsáveis pelo aprimoramento do seu próprio desempenho. Para tal, é necessário que estes internalizem as normas desse gerenciamento, assumindo comportamentos, especialmente competitivos, que os fazem cúmplices da moralidade subjacente ao sistema (Ramírez-Gálvez, 2009, p. 20).

Assim, nos vemos frente a um 'mercado do conhecimento' que, de acordo com Neves e Pronko (2008), está crescentemente se tornando um 'conhecimento para o mercado'. Como sentenciou Leher,

Somente renunciando ao pensamento crítico, é possível edulcorar a ação dos organismos internacionais na América Latina, uma região compungida a exportar capitais para o circuito comandado por Wall Street e Washington, em troca de estagnação, miséria e sofrimento de milhões de pessoas (Leher, 2003, p. 15-16). 
No campo da saúde e do tão caro movimento da reforma sanitária, outras incômodas e (im)pertinentes7 indagações demandam nosso posicionamento. Para citar um exemplo, a crescente ingerência do complexo farmacêutico transnacional, que pauta e financia pesquisas na área biomédica de acordo com seus interesses mercantis (inclusive direcionando, falsificando e mesmo ocultando resultados de pesquisa), não é algo que pode ser menosprezado em termos da (tão cara) 'autonomia' do pesquisador e da ética em pesquisa. Esse poderoso complexo financeiro desenvolveu e aperfeiçoou métodos de cooptação que se infiltram cotidianamente nas instituições públicas de ensino e pesquisa e tornam procedimentos antiéticos absolutamente 'naturalizados'. Atualmente, pouco se questiona o fato de que conferências e congressos médicos, e de saúde em geral, são patrocinados por essas empresas que, entre outras estratégias, cobrem os profissionais, particularmente os médicos, de benesses (viagens, presentes e outros 'mimos'), naturalmente em troca de fidelidade ou silêncio sobre essas problemáticas relações. Sem falar na presença ostensiva de empresas privadas de saúde (laboratórios, seguradoras etc.) no espaço físico das instituições públicas, instituindo concursos e prêmios, construindo auditórios e salas de aula modernas e equipadas (evidentemente, com placas que exibem os patrocinadores), dentre outras estratégias de naturalização dessas relações. Essa 'invasão bárbara' é hoje aceita com uma 'quase' naturalidade; tudo se justifica e é aceito em função dos 'baixos salários' e da crônica falta de recursos para a manutenção das instituições públicas, não mais se colocando a perspectiva de lutarmos coletivamente por salários dignos que possibilitariam um trabalho autônomo e comprometido com o interesse público.

No campo das políticas de saúde, não se pode deixar de mencionar as estreitas relações entre o Estado brasileiro e os interesses do capital internacional, política e financeiramente operacionalizadas através do Banco Mundial, BID e outros organismos similares. Pouco se tem discutido sobre os vários programas do Ministério da Saúde propostos e financiados pelo Banco Mundial (Programa de Aids, Saúde da Família, Reforsus, Vigisus e Doenças e Agravos Não-Transmissíveis/Dant, para citar alguns) ou de 'estudos' patrocinados por esta agência, tais como os que correlacionam a privatização da gestão dos serviços públicos de saúde com a melhoria da qualidade da assistência (Rezende, 2008; Granemann, 2008).

Sobre o papel dessas agências internacionais, Mattos analisa que estas “[...] integram os dispositivos de reprodução da ordem mundial, incluindo aí a sempre mais restrita possibilidade de sua transformação" (Mattos, 2001, p. 379).

Mesmo que alguns autores coloquem este tema em pauta, 8 ele não tem repercutido no debate sanitário, como se houvesse uma 'cegueira' ou um silêncio generalizado a este respeito. Estes programas chegam ao Brasil como empréstimos desta agência que, desta forma, vem definindo prioridades, 
estratégias e políticas para os países dependentes (endividados, o que os torna frágeis nas negociações). E não se trata tão somente de implantar determinados programas de saúde considerados estratégicos, pois, como bem demonstra Rizzotto (2000), Banco Mundial, Fundo Monetário Internacional, Organização Mundial do Comércio e outras agências de 'cooperação' internacional têm exercido, com esta política, um papel central no desmonte do Sistema único de Saúde (SUS), na privatização do setor saúde e na abertura deste rentável 'mercado' para o capital transnacional.

Este é um dos pontos cruciais que, a nosso ver, evidencia de forma contundente a ausência de teoria crítica sobre o capitalismo, pois só é possível desvendar e visibilizar as influências de uma política externa que direciona as políticas 'nacionais' de acordo com os interesses do capital internacional quando se desnuda e compreende a natureza desse sistema em todas as suas complexas articulações, geralmente não perceptíveis nem explícitas.

Mas não só: a 'teoria da práxis' nos conclama à ação política pois, embora conhecer e denunciar sejam passos essenciais para qualquer transformação almejada, é fundamental nos mobilizarmos para, e na, 'práxis'.

\section{A teoria da práxis como ferramenta para o desvendamento de um mundo 'problemático'}

Nunca as sociedades humanas conheceram, como no capitalismo contemporâneo, uma circulação tão generalizada de formas simbólicas e nunca estas exerceram tanta influência sobre as formas de se representar o mundo. Como advoga Thompson, “... a natureza e a abrangência da circulação de formas simbólicas assumiu [atualmente] um aspecto novo e qualitativamente diferente" (Thompson, 1995, p. 9), na medida em que os meios técnicos e as instituições orientadas para a acumulação capitalista possibilitaram a produção, reprodução e circulação das formas simbólicas numa escala antes impensável. O poderoso império do que hoje se denomina 'meios de comunicação de massa', que se expandiu notavelmente através dos progressos na transmissão e codificação eletrônica, é uma questão que não pode ser dissociada de qualquer análise consequente sobre as elaborações simbólicas das sociedades contemporâneas. Nas últimas décadas, sobretudo, com a veloz evolução das telecomunicações e da informática, tornou-se possível nos relacionarmos com o mundo de formas virtuais, aparentemente sem um substrato material (Thompson, 1995; Lacaz, 2001; Simões Barbosa, 2001).

Assim, vivemos em uma sociedade 'ideologizada' que, cada vez mais, exige um conhecimento crítico capaz de desvendar as 'cortinas de fumaça' que recobrem os complexos problemas que enfrentamos e tentamos compreender. Como Romito argumenta, atribuir um 'nome' - neste caso, um 
conceito - torna o fenômeno visível e, assim, perceptível, (re)colocando-o no plano da concretude, viabilizando a crítica e, consequentemente, seu enfrentamento. Assim, “nomear envolve tornar visível o que era invisível, definir como inaceitável o que era aceitável e insistir que o que era naturalizado é problemático" (Romito, 1997, p. 101-113).

A 'teoria da práxis', uma das denominações do materialismo histórico e dialético, nos conclama à unidade indissolúvel entre teoria e ação, inclusive no processo de teorização. Nesta concepção, os fenômenos, tanto naturais quanto sociais, não são abstrações do pensamento, mas fenômenos reais, específicos, em lugar e tempo determinados, sob condições particulares de existência e em movimento, em permanente processo de transformação (Berman, 1997). Decorrente deste posicionamento, postula-se que há um mundo real fora da consciência e cuja existência a precede; que a consciência é um reflexo desse mundo material mas com ele interage, transformando-o e, dialeticamente, transformando-se; que a consciência, o mundo do pensamento e das ideias, em suma, o mundo simbólico, é capaz, através da 'interação prática', de apreender o mundo concreto, compreendê-lo e agir sobre ele, transformando-o. Mas também pode mistificá-lo, encobrindo as causas reais, concretas, materiais, da persistência de desigualdades sociais.

Epistemologicamente falando, a compreensão materialista-dialética requer 'interação' entre pensamento e experiência, o que significa ultrapassar a noção (ainda) hegemônica da observação objetiva, neutra e distanciada. O conceito de 'práxis' fundamenta a concepção marxista sobre o processo de conhecimento onde "A práxis do homem não é atividade prática contraposta à teoria; é determinação da existência humana como elaboração da realidade" (Kosik, 1976, p. 202, grifo no original).

Assim, a existência humana não é apenas 'enriquecida' pela produção humana: "na obra e na criação humana - como em um processo ontocriativo - é que se manifesta a realidade e, de certo modo, se realiza o acesso à realidade" (Kosik, 1976, p. 202). Dessa forma, a 'práxis' revela o ser humano como ser 'ontocriativo', como ser que cria a realidade humano-social e pode, portanto, compreendê-la e transformá-la.

Esse sistema epistemológico, ontológico e político - que pretende conhecer para transformar e transforma conhecendo - confronta e questiona radicalmente a visão dominante de ciência e de conhecimento oriundas do idealismo, do mecanicismo e do positivismo: não existem ideias 'em si', conhecimento 'puro', verdades universais, objetivas, neutras e atemporais. Essas representações da verdade são ideológicas, ou seja, pretendem legitimar e manter um sistema social - o capitalismo - que se apoia na exploração da maior parte da humanidade para assegurar o privilégio de uma elite dominante (Berman, 1999; Simões-Barbosa, 2001). 
Essa concepção de 'práxis' implica, epistemologicamente, que observador e observado, sujeito e objeto de conhecimento, encontram-se em relação, em processo de mútua determinação. Portanto, a realidade é apreendida apenas por um sujeito ativo no processo de conhecer, tanto objetiva quanto subjetivamente, através de envolvimento, conceituação e (inter)ação; a verdade, portanto, não é comprovada como abstração, mas através da interação sensível - através de 'relação' - com o próprio fenômeno. Essa postura filosófica, epistemológica e política implica que o conhecedor compreenda sua própria natureza e suas circunstâncias históricas específicas: ele, assim, se objetiva no processo de conhecer.

Como decorrência, conhecimento crítico e engajamento são indissociáveis. Daí a denominação 'teoria da práxis'.

\section{A tradição marxista na Saúde Coletiva: da hegemonia ao silenciamento}

O campo da Saúde Coletiva, especialmente suas vertentes latino-americanas, teve o marxismo como importante referência teórica, metodológica e política até fins da década de 1980, no período das intensas mobilizações sociais que incluíram a luta pela reforma sanitária brasileira. ${ }^{9}$ A partir de então, assistimos ao gradual banimento deste referencial crítico na análise da sociedade em praticamente todos os campos e áreas do conhecimento. 10 As razões são várias, complexas e não se pretende aqui analisar este processo mas apenas pontuar algumas questões que julgamos importantes, tal como estas se apresenta(ra)m à nossa percepção, experiência e análise.

Ao longo da década de 1990, e até nossos dias, qualquer menção ao marxismo tornou-se explícita ou veladamente censurada ou, na melhor das hipóteses, silenciada. Não se desconsidera aqui, em absoluto, que este fenômeno teve causas políticas reais e concretas, relacionadas ao desmoronamento do sistema dito socialista e, com ele, de uma deturpada concepção do marxismo que, no mínimo, justificou os indesculpáveis equívocos e injustiças perpetradas por aqueles regimes políticos. Mas, assim como Lacaz (2001), advogamos a tese de que, 'junto com a água do banho, foi-se o bebê', já que outras perspectivas interpretativas do marxismo, pautadas no referencial dialético e relacional, sempre estiveram dadas, mesmo que no campo contrahegemônico do próprio marxismo.

Concomitantemente à derrocada do 'socialismo realmente existente', assistimos ao avanço triunfante do neoliberalismo, 11 com amplas consequências e repercussões em todas as esferas da vida social e com profundos reflexos no campo da saúde.

Conforme análise de Laurell (2002), as políticas neoliberais surgem como resposta à crise econômica mundial do final dos anos 1970 e início dos 
1980, quando emerge uma Nova Direita como força político-ideológica. De acordo com a autora,

No âmago do projeto neoliberal repousa a tentativa de se impor um novo padrão de acumulação, [com o intuito de desencadear] uma nova etapa de expansão capitalista que, dentre outras coisas, implicaria um novo ciclo de concentração de capital nas mãos do grande capital internacional (Laurell, 2002, p. 164).

Uma das principais características desta política é a considerável redução dos gastos sociais, o que implica diminuição da oferta de serviços públicos e de subsídios ao consumo popular, contribuindo para deteriorar as condições de vida de uma parcela considerável da população, inclusive amplos setores das camadas médias.

De acordo com Laurell (2002), as políticas neoliberais ressuscitaram um Estado assistencialista, onde cada indivíduo 'compra' os serviços ofertados pelo Mercado, cabendo ao Estado a tarefa de assistir apenas aos 'incapazes' (entenda-se, os excluídos de qualquer renda do trabalho), o que vem provocando, no continente latino-americano, um verdadeiro retrocesso ao século XIX (Laurell, 2002).

No plano ideológico, o neoliberalismo apregoa a necessidade de se reconstituir o mercado como esfera de regulação da vida social e, correlatamente, disseminam-se valores calcados no individualismo, no consumismo e na competição, os quais vêm minando as bases da solidariedade social e do coletivismo.

Contudo, as graves consequências sociais que essas políticas vêm causando terminam por enfraquecer suas possibilidades de êxito. Como pontua Laurell (2002), a História está longe de um fim. O aumento vertiginoso da concentração de riquezas e do contingente dos excluídos de qualquer sistema formal de trabalho e proteção social vem resultando, dentre outras consequências, numa legião de miseráveis que se aglomeram, não mais nas periferias, mas no coração dos centros urbanos, ameaçando a própria 'governabilidade' do sistema. Não há como escapar a esta realidade, inclusive no âmbito de nossas vidas privadas, o que confirma o quanto, e mais do que nunca, necessitamos de instrumentos teóricos críticos que ampliem nossa compreensão destes processos, que estão profundamente 'naturalizados', e instrumentalizem as lutas de enfrentamento. A nosso ver, essa postura implica retomar nossa mobilização - a práxis política - e as lutas em torno do ideário do direito universal à saúde e à educação, o que só pode ser plenamente assegurado em outro modelo de sociedade, justa e igualitária. 


\section{Retomando o marxismo para a análise crítica do campo da saúde}

Se (re)tomamos o processo saúde-doença como campo de análise e assumimos que este expressa, nos planos material e simbólico, objetivo e subjetivo, muitas das contradições sociais, podemos identificar 'sintomas' desta sociedade 'problemática' nas cada vez mais prevalentes patologias do 'corpo e da alma', tais como os distúrbios do comportamento alimentar ou as epidêmicas manifestações da compulsão. Como argumenta Bordo (1997), o sofrimento, na ausência de uma 'voz' política coletiva, pode se expressar através da linguagem corporal, tal como nas doenças psicossomáticas, que podem ser 'lidas' como uma forma de protesto: individual, autorreferido, autodestrutivo. Da insaciável fome consumista, seja das drogas ou de bens supérfluos, à morte pela fome voluntária, como na anorexia, ou como na depressão, a nova 'epidemia do mundo moderno', esses 'sintomas' podem estar denunciando, simbolicamente, a 'fome humana' por afeto, confiança, solidariedade e segurança em um mundo crescentemente desigual, competitivo, individualista, inseguro e violento. Sobre a depressão, que vem se tornando a principal queixa nos consultórios e alimentando o insaciável mercado de psicofármacos, Kehl a interpreta como "[...] a expressão do mal-estar que faz água e ameaça afundar a nau dos bem-adaptados ao século da velocidade, da euforia prêtà-porter, da saúde, do exibicionismo e, como já se tornou chavão, do consumo generalizado" (Kehl, 2009, p. 22, grifos da autora).

Para além das expressões simbólicas e subjetivas que se manifestam nestas patologias 'da alma', e coerentemente com o referencial marxista, que não dissocia os processos simbólicos dos materiais, não se pode desconsiderar o quanto o campo da saúde tornou-se perpassado pelos - e refém dos - interesses mercantis do capital, a tal ponto que, imediatamente após a histórica conquista do direito universal à saúde, consubstanciado na 'Constituição cidadã' de 1988, deslanchou-se uma avassaladora ofensiva de privatização da atenção à saúde, evidenciada através da rápida expansão do segmento suplementar privado e, correlatamente, o 'desmonte' do SUS.

Rizzotto (2000) mostra que estes processos foram, em grande parte, orquestrados 'de fora', com apoio ('técnico' e financeiro) do Banco Mundial que, almejando abrir o cobiçado mercado da saúde para o capital internacional, colaborou ativamente para o desmonte do SUS.

Este ponto de vista é corroborado por Homedes e Ugalde (2005) que, ao analisarem a política de abertura da assistência à saúde para o capital internacional, revelam que

O Brasil contratou de hospitais privados a prestação de uma quantidade razoável de cuidados terciários. Além do mais, aprovou uma lei permitindo que o capital estrangeiro adquirisse hospitais e que seguros de saúde estrangeiros e organizações 
de manutenção da saúde oferecessem serviços que, até então, estavam restritos às organizações/instituições brasileiras e ao setor público. Logo depois da aprovação da lei, várias empresas norte-americanas tiraram vantagens dessa liberalização e começaram a ofertar seguros de saúde e assistência para as classes médias e alta (Homedes e Ugalde, 2005, p. 85, tradução nossa, revisada por Karen Giffin). ${ }^{12}$

Os autores esclarecem quem são os principais beneficiários dessas políticas:

A pergunta que tem que ser respondida é por que, em vista da crescente evidência de que as reformas neoliberais não atingiram os objetivos pretendidos, o Banco Mundial continua a promover seu modelo de reforma da saúde. Identificar os beneficiários das reformas neoliberais clarifica as razões da persistência do Banco Mundial na promoção de políticas fracassadas. Os principais beneficiários incluem empresas transnacionais, firmas de consultoria e o próprio staff do Banco Mundial (Homedes e Ugalde, 2005, p. 92, tradução nossa, revisada por Karen Giffin).13

Um outro aspecto a ser considerado é a permanência, e mesmo o fortalecimento, do 'modelo biomédico', como denominado o paradigma científicoideológico da Medicina ocidental que orienta o modelo de atenção à saúde. Enquanto corpo de conhecimentos científicos elaborados a partir de determinada concepção de corpo - corpo-máquina, biológico, individual, universal e atemporal - este modelo é concomitante e funcional à emergência e ao desenvolvimento do capitalismo. A concepção mecanicista de corpo, que o ancora conceitualmente, vem contribuindo para a disciplinarização dos corpos, 'moldando' as classes trabalhadoras para os processos de trabalho explorado e alienado, onde um corpo domesticado, socializado para exercer as funções segmentadas, monótonas e repetitivas da produção industrial taylorista/fordista, foi condição sine qua non para a instauração do capitalismo (Boltanski, 1979; Xavier; Ávila; Correa, 1989; Costa, 1989; Berman, 1997; Besse, 1999; Brito, 2000; Simões Barbosa, 2001; Vieira, 2002).

O corpo feminino é emblemático deste processo, pois nele se exerce(ra)m diretamente mecanismos de controle sobre a reprodução social. Por isso, foi um dos alvos prioritários da intervenção médica ao longo dos últimos dois séculos. Não casualmente, o feminismo, em seu momento inaugural (ainda) questionador do capitalismo, elaborou uma rica vertente de crítica radical aos modelos científico-ideológicos de produção do conhecimento em saúde, esquadrinhando e denunciando os mecanismos através dos quais se exerce o poder político-científico sobre o corpo feminino. A usurpação, e posterior institucionalização, de saberes populares sobre a saúde, especialmente aqueles produzidos e utilizados pelas mulheres, foi parte estratégica deste processo (Berman, 1997; Giffin, 1995; Xavier; Ávila; Correa, 1989; Vieira, 2002). 
No plano da subjetividade e das representações simbólicas, há que se considerar a persistência, e mesmo o fortalecimento, de uma ideologia médica que destitui o corpo de seus determinantes sociais, culturais, raciais e de gênero, assim como destitui a população de direitos historicamente conquistados. A ideologia médica exercita-se através de um discurso pedagógico exercido no cotidiano da assistência à saúde que, destituindo de valor o saber empírico popular e, desta forma, re-afirmando a 'inferioridade' social da classe trabalhadora, mantém e reproduz as desigualdades de classe, de gênero e de raça/etnia, colaborando para os processos pedagógico-ideológicos de reprodução social (Boltanski, 1979; Simões Barbosa, 2001).

Muitos outros temas e ângulos de análise que revelam a atuação do capitalismo no campo da saúde poderiam ser mencionados, mas, para os objetivos deste ensaio, julgamos que os citados são suficientes para corroborar as teses levantadas e confirmar a imperiosa necessidade de retomarmos a teoria da práxis para o enfrentamento e a superação do capitalismo.

\section{Considerações finais}

O marxismo, enquanto 'teoria da práxis', não dissocia a produção de conhecimentos teóricos da ação política transformadora. Para os que compartilham desse paradigma de 'conhecimento engajado', não bastam discursos e declarações de intenções, mesmo que eles insinuem, revelem ou mesmo denunciem questões 'problemáticas'. A gravidade dos problemas que hoje afetam nosso mundo não deixa margem para omissões, acomodação ou alienação.

Posicionamento e atuação contra esse sistema pressupõem, dentre outras ações políticas, nossa própria organização como trabalhadores/as - da educação e da saúde - e o estabelecimento de alianças e solidariedades com os demais trabalhadores e segmentos sociais envolvidos na luta contra o capitalismo. No âmbito das instituições de ensino e pesquisa, é fundamental lutarmos contra os processos de privatização em curso, inclusive contra o estabelecimento, sutil ou explícito, da lógica competitiva, privatista e individualista que rege nossos processos e relações de trabalho. Esta postura demanda alinhamento incondicional com políticas universais de educação e saúde articuladas às demais políticas públicas, o que exige um Estado voltado para o bem coletivo.

O campo da saúde, que lida com questões tão caras à vida humana sofrimento, dor, superação, solidariedade - é emblemático. Ele exige nosso compromisso com valores éticos e sociais que resultam de muitos séculos de história, de lutas e conquistas humanas. Não podemos, pois, permitir que os processos de banalização e mercantilização da vida nos transformem em 
profissionais, pesquisadores e pessoas insensíveis, indiferentes ou alienados em relação ao sofrimento e à injustiça.

Como propõe Lacaz (2001), é mais do que necessário retomar nosso ativismo enquanto sujeitos na e da saúde coletiva, de forma que a saúde

... como direito (coletivo) de cidadania deixe de ser apenas retórica e assuma, a partir da ação política, o caráter de uma utopia que precisa estar novamente inscrita nas bandeiras de luta do movimento social, particularmente em tempos nos quais é preconizado o estado mínimo como corolário das políticas neoliberais que procuram desregulamentar direitos sociais básicos, os quais, em países como o Brasil, nunca foram usufruídos pela maioria da população" (Lacaz, 2001, p. 241).

Portanto, devemos ter a coragem e ousadia de novamente levantar a bandeira do socialismo, demonstrando, mais uma vez, que o direito à saúde é ficção abstrata e retórica sem igualdade e justiça social.

\section{Notas}

1 Professora adjunta do Instituto de Estudos em Saúde Coletiva da Universidade Federal do Rio de Janeiro (Iesc/UFRJ), Rio de Janeiro, Brasil. Doutora em Ciências pela Escola Nacional de Saúde Pública Sérgio Arouca, Fundação Oswaldo Cruz (Ensp/Fiocruz). <regina@iesc.ufrj.br> Correspondência: Instituto de Estudos em Saúde Coletiva da Universidade Federal do Rio de Janeiro (Iesc/UFRJ), Praça Jorge Machado Moreira, 100, Cidade Universitária, Rio de Janeiro, Brasil, CEP 21941-598.

2 Este trabalho contou com valiosos comentários de Karen Giffin, José Antônio Martins Simões e Mary Jane de O. Teixeira.

3 O conceito marxista de ideologia é aqui compreendido em seu sentido negativo, crítico, ou seja, a ideologia manifesta-se quando os sentidos assumidos pelas formas simbólicas, que se expressam nas falas cotidianas, nas representações e nos discursos complexos, servem para manter relações de poder que sustentam e perpetuam os mecanismos de exploração e dominação (Thompson, 1995; Simões Barbosa, 2001).

4 Não é objetivo aqui analisar as correntes pós-estruturalistas, mas julgo importante observar que essas 'teorias', embora não apontem para qualquer transformação real, expressam um desencantamento com a sociedade capitalista avançada, um 'mal-estar' da modernidade tardia.

5 Esse termo é inspirado em Giffin, que o utiliza em seu artigo "Produção do conhecimento em um mundo 'problemático': contribuições de um feminismo dialético e relacional" (Giffin, 2006). 
6 Expressão usada por Silva no artigo “A sua revista tem Qualis?” (Silva, 2009).

7 Este termo é inspirado em Virgínia Fontes, que o utilizou no título de seu livro Reflexões im-pertinentes: história e capitalismo contemporâneo (Fontes, 2005).

8 Ver, por exemplo, Matta, G.C. A organização Mundial da Saúde: do controle de epidemias à luta pela hegemonia. Trabalho, Educação e Saúde, v. 3 n. 2, p. 371-396, 2005; Rizzotto, M.L.F. O Banco Mundial e as políticas de saúde no Brasil nos anos 90: um projeto de desmonte do SUS. Campinas: Unicamp, 2000

${ }^{9}$ A imensa e inestimável contribuição de tantos sanitaristas brasileiros e latino-americanos que tiveram no marxismo sua referência teórica e política é aqui plenamente reconhecida, mas, por não ser este o objetivo deste trabalho e por falta de espaço, não abordaremos o tema.

10 Existem muitos pesquisadores, grupos de pesquisa e até mesmo instituições que, individual ou coletivamente, têm no marxismo sua referência conceitual e política e, coerentemente, continuam a atuar nos movimentos sociais de enfrentamento ao capitalismo. O que está sendo argumentado é que esses valorosos grupos e colegas encontram-se, na conjuntura atual, com poucas possibilidades de pautar essa perspectiva crítica nas discussões e debates acadêmicos e científicos.

11 O termo é aqui compreendido em sentido amplo e considerado em suas dimensões econômica e política (Chesnais, 1996): da busca de estabelecimento de um novo padrão de acumulação visando nova expansão do sistema capitalista (Laurell, 2002) à poderosa dominação ideológica promovida pela indústria cultural' midiática, que 'naturaliza' e 'universaliza' - como se decorrentes do devir histórico - categorias e termos tais como Estado mínimo, Mercado, flexibilização, ajustes estruturais, desregulamentação etc. (LimoeiroCardoso, 2000).

12 No original: Brazil contracted out to private hospitals the delivery of a sizeable amount of tertiary care. In addition, it passed a law allowing foreign capital to purchase hospitals, and foreign health insurance and health maintenance organizations to provide services that until then had been restricted to Brazilian firms and the public sector. Soon after the passage of the law, several US firms took advantage of the liberalization, and began to offer health insurance and care to the middle and upper classes.

13 No original: The question that needs to be asked is why, in view of the mounting evidence that neoliberal reforms do not accomplish the intended goals, the WB [World Bank] continues to promote its health reform model. Identifying the beneficiaries of the neoliberal reforms clarifies the reason for the WB's persistence in promoting unsuccessful policies. The principal beneficiaries include transnational corporations, consultant firms, and the WB's own staff. 


\section{Referências}

BERMAN, Ruth. Do dualismo de Aristóteles à dialética materialista: a transformação feminista da ciência e da sociedade. In: JAGGAR, A. M.; BORDO, Susan R. (Org.). Gênero, corpo, conhecimento. Rio de Janeiro: Record/Rosa dos Tempos, 1997. p. 241-275.

BESSE, Susan K. Modernizando a desigualdade: reestruturação da ideologia de gênero no Brasil, 1914-1940. Tradução de Lólio Lourenço de Oliveira. São Paulo: Edusp, 1999.

BOLTANSKI, Luc. As classes sociais e o corpo. Rio de Janeiro: Graal, 1979.

BRITO, Jussara C. Enfoque de gênero e relação saúde/trabalho no contexto de reestruturação produtiva e precarização do trabalho. Cadernos de Saúde Pública, Rio de Janeiro, v. 16, n. 1, p. 195-204, jan./mar., 2000.

BORDO, Susan. O corpo e a reprodução da feminilidade: uma apropriação feminista de Foucault. In: JAGGAR, A. M.; BORDO, S.R. (Org.). Gênero, corpo, conhecimento. Rio de Janeiro: Record/Rosa dos Tempos, 1997.

BOURDIEU, Pierre; WACQUANT, LoÏq J. D. A nova bíblia de Tio Sam. Le Monde Diplomatique, maio 2000. Disponível em: <www. forumsocialmundial.org.br $>$. Biblioteca das Alternativas. Acesso em: mar. 2001

BOURDIEU, Pierre. Um saber comprometido. Le Monde Diplomatique (edição portuguesa), n. 35 ano 3, fev. 2002, p. 3. Lisboa: Editora Campo da Comunicação, 2002.

CASTRO, Mary Garcia. Marxismo, feminismos e feminismo marxista: mais que um gênero em tempos neoliberais. Crítica Marxista, Campinas, n. 11, Unicamp, 2000, p. 98-108.

CHESNAIS, François. A mundialização do capital. São Paulo: Xamã, 1996.

COSTA, Jurandir Freire. Ordem médica e norma familiar. 3. ed. Rio de Janeiro: Editora Graal, 1989.
FONTES, Virgínia. Reflexões Im-Pertinentes: história e capitalismo contemporâneo. Rio de Janeiro: Bom Texto, 2005.

GIFFIN, Karen. Estudos de gênero e saúde coletiva: teoria e prática. Saúde em Debate, Rio de Janeiro, n. 46, p. 29-33, 1995.

Pobreza, desigualdade e equidade em saúde: considerações a partir de uma perspectiva de gênero transversal. Cadernos de Saúde Pública, Rio de Janeiro, 18, supl., p. 103-112, 2002.

Produção do conhecimento em um mundo 'problemático': contribuições de um feminismo dialético e relacional. Estudos Feministas, Florianópolis, n. 14, v. 3, p. 635653, set./dez. 2006.

GRANEMANN, Sara. Fundações estatais: projeto de estado do capital. In: BRAVO, M.I.S. et al. (Org.). Politica de saúde na atual conjuntura: modelos de gestão e agenda para a saúde. 2. ed. rev. e ampl. Rio de Janeiro: Rede Sirius/Adufrj-Ssind, 2008. p. 36-39.

HOMEDES, Núria; UGALDE, Antonio. Why neoliberal health reforms have failed in Latin América. Health Policy 71 (2005), 83-96. Disponível em: <www.journals. elsevierhealth.com/periodicals/heap/article/ S0168-8510(04)00117-4/abstract>. Acesso em: 26 out. 2009.

KEHL, Maria Rita. O tempo e o cão: a atualidade das depressões. São Paulo: Boitempo, 2009.

KOSIK, Karol. Dialética do concreto. Rio de Janeiro: Paz e Terra, 1976.

LACAZ, Francisco Antônio de Castro. O sujeito $\mathrm{n}(\mathrm{d})$ a saúde coletiva e pós-modernismo. Ciência \& Saúde Coletiva, Rio de Janeiro, v. 6, n. 1, 2001. Disponível em: <www.scielo.br/ scielo.php?script $=$ sci_arttext $\&$ pid $=$ S1413$81232001000100019 \& \operatorname{lng}=$ pt $\& n r m=$ iso $>$. Acesso em: 26 mar. 2010. 
LAURELL, Asa Cristina. Avançando em direção ao passado: a política social do neoliberalismo. In: Asa C. Laurell (Org.). Estado e politicas sociais no neoliberalismo. 3. ed. São Paulo: Cortez, 2002. p. 151-178.

LEHER, Roberto. Reforma universitária do governo Lula: protagonismo do Banco Mundial e das lutas antineoliberais. Folha Dirigida, Rio de Janeiro, p. 15, 16 dez. 2003.

LIMOEIRO-CARDOSO, Miriam. Ideologia da globalização e descaminhos da ciência social. In: GENTILI, Pablo (Org.) Globalização excludente: desigualdade, exclusão e democracia na nova ordem mundial. Petrópolis: Vozes; Buenos Aires: Clacso, 2000, p. 96-127.

LUZ, Madel T. Prometeu acorrentado: análise sociológica da categoria produtividade e as condições atuais da vida acadêmica. Physis: Revista de Saúde Coletiva, Rio de Janeiro, v. 15, n.1, p. 39- 57, 2005.

MATTA, Gustavo C. A Organização Mundial da Saúde: do controle de epidemias à luta pela hegemonia. Trabalho, Educação e Saúde, Rio de Janeiro, v. 3 n. 2, p. 371-396, 2005

MATTOS, Ruben A. de. As agências internacionais e as políticas de saúde nos anos 90: um panorama geral da oferta de idéias. Ciência \& Saúde Coletiva, Rio de Janeiro, v. 6, n. 2, p. 377-389, 2001.

NEVES, Lúcia M. Wanderley; PRONKO, Marcela A. O mercado do conhecimento e o conhecimento para o mercado: da formação para o trabalho complexo no Brasil contemporâneo. Rio de Janeiro: EPSJV, 2008.

OLIVEIRA, Marcos B. de. Ciência: força produtiva ou mercadoria?. Crítica Marxista, n. 21, Campinas: Unicamp, p. 77-96, 2005.

RAMÍREZ-GÁLVEZ, Martha. Apresentação. Algumas considerações sobre a cultura da avaliação. Mediações, v. 14, n. 1, p. 117-124, jan./jun. 2009.
REZENDE, Maria Aparecida P. O modelo de gestão do SUS e as ameaças do projeto neoliberal. In: BRAVO, M.I.S. et al. (Org.). Politica de saúde na atual conjuntura: modelos de gestão e agenda para a saúde. 2. ed. rev. e ampl. Rio de Janeiro: Rede Sirius/ Adufrj-Ssind, 2008. p. 25.

RIZZOTTO, Maria Lúcia F. O Banco Mundial e as politicas de saúde no Brasil nos anos 90: um projeto de desmonte do SUS. Tese (Doutorado em Saúde Coletiva) - Campinas, Unicamp, 2000.

ROMITO, Patrícia. Trabalho, maternidade e saúde das mulheres: algumas notas metodológicas. In: SCAVONE L.; BATISTA, L.E. (Org.). Trabalho, saúde e gênero na era da globalização, Goiânia: AB, 1997, p. 101-113.

SANTOS, Aparecida de F. T. Entre a cooptação e a repressão: capital e trabalho nas reformas educacionais latino-americanas. In: GOMES, Cláudio (Org.). Temas do Ensino Médio: trilhas da identidade. Rio de Janeiro: EPSJV/Fiocruz, 2004. p. 49-64.

SILVA, Antônio Ozaí da. A sua revista tem Qualis? Mediações, v. 14, n. 1, p. 117-124, jan./jun. 2009.

SIMÕES BARBOSA, Regina H. Mulheres, reprodução e Aids: as tramas da ideologia na assistência à saúde de gestantes HIV+. Tese (Doutorado em Saúde Pública) - Rio de Janeiro: Escola Nacional de Saúde Pública, Fundação Oswaldo Cruz, 2001.

THOMPSON, John B. Ideologia e cultura moderna: teoria social crítica na era dos meios de comunicação de massa. Petrópolis: Vozes, 1995.

VIEIRA, Elizabeth M. A medicalização do corpo feminino. Rio de Janeiro: Editora Fiocruz, 2002.

XAVIER, Dulcinéia; ÁVILA, Maria B.; CORREA, Sônia. Questões feministas para a ordem médica: o feminismo e o conceito de 
saúde integral. In: LABRA, Maria E. (Org.). Mulher, saúde e sociedade no Brasil. Petrópolis: Vozes; Rio de Janeiro: Abrasco, 1989.

WOOD, Ellen M. Em defesa da História: o marxismo e a agenda pós-moderna. Crítica Marxista, Campinas, Unicamp, p. 118-129, 1996.

Recebido em 08/02/2010 Aprovado em 19/03/2010 